\title{
How have recent changes in the NHS affected perinatal audit?
}

\author{
Miranda Mugford, Jean Chapple
}

In the field of maternity and newborn care there has been a long tradition of monitoring outcomes of care and a growing interest in ensuring that care given to women and their babies is effective and efficient. The methods for achieving this have not, however, been a formal part of national and local health policy and management. Recent changes in the NHS have been accompanied by policy statements placing particular emphasis on the need for effective and efficient health care provision. Clinical audit is one of the mechanisms through which it was envisaged that this would be ensured. ${ }^{1}$ In this paper, we briefly discuss the meaning of audit and some of the recommendations and corresponding initiatives to encourage audit at national and health authority level. We then review the background to audit in perinatal care, and illustrate from our own work some of the implications of recent changes at unit level. Finally, we consider what further developments may be expected.

\section{What is audit?}

Although the Department of Health and NHS management support for audit is of fairly recent origin, it is not a new concept in health care. ${ }^{2}$ In the early $1980 \mathrm{~s}$, the question of medical audit was already being addressed in the fields of epidemiology and public health, and the concept of the 'audit cycle' was introduced into the health services research literature. ${ }^{34}$ The audit cycle is a description of a process of agreeing standards for practice, reviewing information about practice against standards, making changes in practice where necessary, and then repeating the process of review of standards and monitoring practice. At this stage, audit was clearly defined as including a commitment to implementation of findings where practice diverged from ideal standards. The question of relating clinical or medical audit to resource management, however, was not explicitly included in the definition. When audit was recommended within the white paper: Working for Patients, it was defined as: 'the systematic critical analysis of the quality of medical care, including the procedures used for diagnosis and treatment, the use of resources, and the resulting outcome and quality of life for the patient'. ${ }^{1}$ Although costs of resources used as a result of clinical practice received explicit mention, this definition no longer contains any commitment to implementation of the results of audit. This is now seen as part of the role of continuing education, although it is not clear how the two processes are to be linked.

A report of the Standing Medical Advisory Committee to the Department of $\mathrm{Health}^{5}$ included the following requirements for medical audit:

- Audit should have the objective to improve the quality of care doctors provide for their patients;

- Audit should be systematic and structured;

- Audit should use quantitative methods;

- Audit should result in change, where appropriate, in organisation or care provision; therefore

- Audit should include follow up to ensure implementation of results;

- Audit should include a record of meetings held, with attendance recorded and a note of subjects covered and recommendations made;

- Audit should be undertaken by all doctors, and colleges should consider what actions should be directed towards persistent non-attenders; however

- Audit should be confidential, educational, and not disciplinary.

The important role of professional leaders in setting and maintaining standards for good practice and for education within the profession is acknowledged in research studies of different approaches to quality assurance in clinical care. ${ }^{6}$ The Department of Health Audit Initiative included an invitation to the medical colleges to bid for funds to develop their role in support of audit within their professions. Working for Patients and other documents from Department of Health have referred specifically to 'doctors' and to 'medical' audit, rather than 'health professionals' and 'clinical audit', thus emphasising the professional boundaries and making more difficult the establishment of an interdisciplinary patient based approach to ensuring quality of care. Overcoming professional boundaries is particularly important for audit in the perinatal field, where midwives, general practitioners, obstetricians, and paediatricians are all responsible for the quality of care of the same women and babies. Department of Health funding has more recently been 
extended to colleges representing professions allied to medicine.

The fragmentation of responsibilities for quality of care was furthered by the parallel initiatives in quality assurance ${ }^{7}$ and the Patients' Charter $^{8}$, which were interpreted primarily as nursing and general management responsibilities. Resource management, although intended to bring clinical and financial decision making together, has been developed independently of audit. ${ }^{9}$

The separation of the different initiatives concerned with the cost and quality of care and outcomes has been compounded by the failure to develop information systems that could help clinical audit. Emphasis for accounting purposes on counting numbers of finished consultant episodes has resulted in systems that give lower priority to record linkage, and cannot easily provide information about the experience of individual patients, or relate care to final outcomes. ${ }^{1011}$ The lack of information for audit from routine information systems is in part the result of changes following the review of NHS information needs in the early 1980 s. $^{12}$ Implementation of the recommendations of this review resulted in the scrapping of old hospital data collection systems, but introduction of new systems was hampered by lack of funding and by the organisational changes following Working for Patients. Until 1985, national statistics were available about maternity care, based on a $10 \%$ sample of all births. Since then, national data on maternity care are being collected for all births, but as they are still incomplete they are not published, except in reply to questions in parliament. ${ }^{13}$

Evaluation of the audit initiative is difficult because it was only one part of legislation aimed at radically changing the NHS. Therefore any changes occurring cannot be considered in isolation from the impact of the other measures that have been implemented. Most importantly, the separation of the functions of purchasing and providing health care has resulted in, as yet, unclear responsibilities for monitoring outcomes of care.

Developments in clinical audit should also be considered alongside the changing arrangements for research funding and commissioning within the NHS. ${ }^{14}$ It is the stated aim of the NHS research initiative that the NHS should become a knowledge based organisation, and this implies that there could be a considerable overlap between audit and research. As well as generating hypotheses to be tested in formal research studies audit may also be a vehicle whereby research evidence is adopted in practice. Every health region in England now has a directorate of research and development, and in some regions audit funds are controlled by the same directorate.

To date it has been estimated that over $£ 100 \mathrm{~m}$ has been spent on audit in the UK. ${ }^{15} 16$ Earmarked money was made available to royal colleges, and to regions and districts to fund pilot projects and then to institutionalise audit within the NHS management structure. Informal and formal networks for discussion of audit projects have grown up within some regions, and the King's Fund has established an Audit Information Unit. ${ }^{17}$ Publications devoted to the subject are increasing in number.

\section{Background to perinatal audit}

Current approaches to monitoring the health of childbearing women and their babies have their origins in nineteenth century concerns about public health and the insanitary living conditions of the poor. ${ }^{18}$ The availability of statistics from civil registration, resulting from Acts of Parliament in 1836 for England and Wales, 1855 in Scotland, and 1864 in Ireland, made this exercise much easier, and publication of annual statistics about births and infant and maternal deaths has for many years been a central part of the role of the General Register Office, now incorporated into the Office of Population Censuses and Surveys (OPCS), who also supply data to district health authorities. Because management data are all now based on financial years, whereas registration data are collated by calendar year, comparisons of data from different systems causes difficulties for district information departments and others wishing to use routinely collected data to monitor health provision and out-4 comes.

Concerns about failure of mortality rates to fall or wide geographical differences in mortality rates have from time to time sparked off national initiatives to investigate the causes. In the 1920 s and $1930 \mathrm{~s}$, maternal mortality was the subject of specific inquiries. From 1932 medical officers of health monitored maternal deaths, and in 1952 the lead passed to clinicians in the system of Confidential Enquiries v. into Maternal Deaths begun in England and Wales. ${ }^{18}$ In the early 1970 s the possibility of similar inquiries into the very much largen numbers of infant or perinatal deaths was back on the agenda. Some health districts and regions began to establish local surveys and inquiries into stillbirths and infant deaths, although many of these were one off exer is cises. ${ }^{19}$

In 1980 , a working party met under the auspices of the Royal College of Obstetricians and Gynaecologists (RCOG) to discuss perinatal audit and surveillance. ${ }^{20}$ At this stage, 'audit' was not exclusively concerned with the quality of clinical care, but with determining the factors that might influence mortality risks, including access to and quality of care. The RCOG working party drew from the disciplines of public health, statistics, and epidemiology, as well as midwifery, obstetrics, and paediatrics, and provided examples for better population monitoring at district level. The report also raised important questions about the effectiveness of clinical care, and the mechanisms to monitor this, including seeking the views of the women who use the maternity services. The practice in many hospitals of holding meetings to review cases followed by perinatal death was not held to be the best approach to audit, especially if conducted in a 
negative atmosphere or where the exercise was dedicated to finding 'avoidable' factors, in the absence of evidence about what happened in similar cases where babies did not die. Nevertheless, perinatal mortality meetings have become a tradition in most maternity and neonatal units, and are held by some to demonstrate that the specialties of obstetrics and gynaecology and paediatrics are well ahead in the field of medical audit.

Two recent national initiatives were set up to make fetal and infant deaths the subject of formal inquiry: regional surveys of stillbirths and infant deaths and the Confidential Enquiry into Stillbirth and Deaths in Infancy (CESDI). These were set up to satisfy Department of Health requirements after the government's reply to the House of Commons Social Services Committee report on stillbirth and neonatal and infant mortality. ${ }^{21}$ CESDI might yield detailed information about individual deaths that is not available from health service data systems or from civil registration. There has been and still is concern, however, that inquiries into individual deaths may not be the best approach to finding the causes of and preventing stillbirths and infant deaths. ${ }^{22} 23$ Data about the whole population of births will still need to be derived from routine systems, but attention will be diverted from the quality of these data. A current example of such a problem is that the proportion of births in England and Wales where no birth weight was recorded on the birth record increased in 1989.

As mortality rates have fallen, the relative importance of the health status of survivors has increased. The relationship between perinatal care and long term disability has been debated for many years, but statistics have not routinely and consistently been collected at national level that could inform the debate. In Scotland, England and Wales, the establishment of regional and more local studies are beginning to provide important data. ${ }^{24}$ Health authorities are meeting considerable costs as courts make awards to families of disabled children; they may thus be motivated not only to be aware of the quality of care given at the time of birth, but to support more comprehensive long term population based follow up of births to their residents. A recent report from the Audit Commission lends weight to the need to move from use of mortality indicators and to include long term outcome data in assessment of care in the perinatal period. ${ }^{25}$

The NHS management executive has encouraged local health authorities to take account of the views of service users. ${ }^{826}$ This had already been advocated for maternity services, ${ }^{20}$ and methods for surveying women's views about their care have been developed by OPCS. ${ }^{27}$ The health of women during pregnancy and after childbirth has received little attention in routine audit of care, although caesarean section is a common topic for audit in obstetrics. Individual studies show that there is scope for audit to be developed to assess effects of care on women's health, ${ }^{28}$ but there are considerable problems to be overcome in collecting adequate data. Routine data from community and hospital systems do not provide much information about women's health after childbirth.

Recognition of the value of statistics about hospital care in monitoring quality has a long tradition. In England, however, routine statistics collected nationally on maternity and neonatal care have been subject to the many changes in NHS policy and organisation, and as a result are still not routinely available. ${ }^{11}$ This contrasts with the picture in Scotland, and at least five of the 14 English health regions where systems have been set up to collect, analyse, and feed back such data for the purpose of monitoring and improving the maternity and/or neonatal services. There are now many examples of the use of routinely collected hospital data for audit within a single maternity unit. ${ }^{29}$

The professional colleges have taken on a role in audit of care. A survey in 1986 reported several initiatives by different colleges in setting standards and guidelines, and monitoring safety and quality of care. ${ }^{30}$ The RCOG has an audit committee, previously the statistics and epidemiology subcommittee, and has set up an audit unit in Manchester under the directorship of Michael Maresh that produces occasional bulletins. Both the RCOG and the British Paediatric Association have published guidelines to good practice on specific topics. ${ }^{31}$ The Royal College of Midwives has also recently announced plans for an audit unit, and has been granted funds by the Department of Health for an audit of independent midwifery.

Audit requires not only information about practice, but knowledge about what practices are effective. In the field of maternity and neonatal care, the results of regularly updated systematic review of research evidence have now been available to professionals in both book and electronic form since $1989 .{ }^{32} 33$ Evidence that this source is sometimes used in setting standards is illustrated in quotation of the relevant reviews in the college guidelines for practice.

\section{Perinatal audit in one English NHS region}

In research funded under the audit initiative, we have had the opportunity to observe audit practice within maternity units in the North West Thames region of England between 1990 and 1992. The region is unusual in that all its maternity units have the same computerised maternity information system, the St Mary's Maternity Information System (SMMIS). ${ }^{34}$ Although the installation of the system has provided a useful management function at unit level, as well as an excellent database for research, it is not clear whether it was also used in audit at unit level.

During an eight month period in 1990 , our colleagues, Philip Banfield, an obstetric research fellow, and Moira O'Hanlon, a sociologist, visited the maternity units in the region, observed audit meetings, and interviewed senior staff about local audit practice and the 
use of the information system. They found that in two thirds of the units, audit at unit level still took the form of clinical meetings for the review of cases where a perinatal death or 'near miss' had occurred. Three units were also holding regular caesarean section audit meetings, and other units stated an intent to establish specific 'audit' sessions. At the time of the study, the observed meetings had many of the recommended elements of clinical audit. The meetings were held regularly and were multidisciplinary in that midwives, paediatricians, and obstetricians attended, although midwives did not present topics at meetings and seldom spoke. The presenters usually respected confidentiality and many of the meetings were usually held in a constructive atmosphere; however, meetings observed did not usually measure up to all the recommendations of the Department of Health. In particular, meetings were likely to be cancelled at short notice, senior staff were least likely to attend, available data from SMMIS for quantitative background material were only used in about half the units, and there was seldom discussion of the implications for future practice or further investigation. None of the meetings contained discussion of information about costs of care or allocation of unit resources.

Although it is unlikely that information alone will change practice, ${ }^{35}$ it is even more unlikely that change in practice will even be considered in the absence of information. Previous encouragement at regional meetings of obstetricians in the North West Thames region led to the publication and distribution of regional statistical reports comparing clinical practice at each of the maternity units. ${ }^{3637}$ We surveyed senior obstetric and midwifery staff for knowledge of key statistics that we included in the reports. These questions were asked, firstly, before these reports had been distributed, and then again after the second one had been produced. We found in the first survey that staff were not well informed about their own unit's workload, obstetric intervention rates, or any measures of outcome. ${ }^{38}$ Some could not give us the number of annual births at the unit to the nearest 100 . There were some changes in knowledge in the second questionnaire and more staff were able to attempt an answer; in addition, more were able to give an answer within $10 \%$ of the actual number. Not surprisingly, midwives and medical staff were familiar with different statistics; few obstetricians were able to give breastfeeding rates at discharge for example, and few midwives could give accurate induction and instrumental delivery rates. The biggest changes between the two surveys were in the knowledge of numbers of annual births, epidural rates, episiotomy rates, and, among midwives, breast feeding rates.

\section{Where next?}

Researchers at Brunel University monitored the changes following the audit initiative. They looked at general medicine in sample sites in one region. They also surveyed audit assistants nationally and have recently published a report presenting their findings. ${ }^{16}$ They conclude that although the infrastructure for audit is in place in the form of audit committees and support staff, it is still a 'frail plant', championed by enthusiasts, but considered by most to be marginal in importance to the work of the unit. Audit projects were, on the whole, self contained and small; they did not, or could not, make use of routine data sources; meetings were not in general attended by senior staff, and were not usually followed by management action to implement change. The authors also found that medical audit is confined within specialties and tends not to cross professional boundaries. They observed that questions about resource implications of care policies have not yet been addressed in the audit process. In conclusion, they emphasised the lack of clarity about the purpose of audit and asked whether it is a process to monitor the provision of quality care to satisfy 'purchasers'; a professional education exercise to improve standards of practice by individuals; or a management process to ensure cost effective use of resources in a hospital. They suggest that the easy availability of money for audit has allowed audit to be introduced without addressing this question.

Whether or not the frail plant of critical evaluation of practice takes root in the NHS is of paramount importance. Unless it does, it is unlikely that the services provided will be the best. There are several factors that may influence the development of clinical audit. Firstly, the culture within units providing health care will determine the priority given to audit; but this may be helped by adequate back up from audit staff and from well supported routine information systems. Secondly, and more importantly, purchasers of services may begin to specify the need for audit results in their contracts with providing units. Even if at first this is ignored as being only a minor irritation, general managers will not see it as such if lack of audit activity could lead to the loss of a contract.

Thirdly, and perhaps most fundamentally, unless good quality statistical information is easily available, audit cannot advance from the isolated one off studies where it is usually confined at present. It is difficult for such studies to be the basis for repeated re-evaluation of practice, or for comparisons between different settings for care. There are many barriers to the development of the sort of information that would help audit to flourish. The new financial arrangements for NHS trusts and fundholding general practices are often associated with the development of 'in-house' systems, which for both technical and commercial reasons stand in the way of comprehensive maternity information, including care at both primary and hospital levels.

We acknowledge and thank those at the department of obstetrics and gynaecology at St Mary's Hospital and Medical School with whom we have collaborated, and especially Philip Banfield, Richard Beard, and Moira O'Hanlon. We thank many colleagues for their comments on drafts of this paper. Our work is funded by the Department of Health (MM) and the North West Thames Regional Health Authority (JC). 
1 Department of Health. Working for patients. London: HMSO, 1989. (Cm 555.)

2 Black N. Quality assurance of medical care $f$ Public Health Med 1990; 12: 97-104.

3 Shaw CD. Aspects of audit: I. The background. BMF 1980; 280: 1256-8.

4 Fowkes FGR. Medical audit cycle. Med Educ 1982; 16: 228-38.

5 Standing Medical Advisory Committee, Department of Health. The quality of medical care. London: HMSO, 1990

6 Lomas J, Haynes RB. A taxonomy and critical review of tested strategies for the application of clinical practice recommendations; from 'official' to 'individual' clinical policy. Am F Prev Med 1988; 4 suppl: 77-94.

7 Department of Health. New quality drive in NHS. (Press release 23 January 90/34.) London: Department of Health, 1990.

8 Department of Health. The patient's charter: raising the standard. London: HMSO, 1992.

9 Buxton M, Packwood T, Keen J. Final report of the Brunel University evaluation of resource management. London: Department of Health, 1989.

10 Radical Statistics Health Group. NHS reforms: the first six months - proof of progress or a statistical smokescreen? BMF 1992; 304: 705-9.

11 Macfarlane AJ. Sources of data. In: Maresh M, ed. Audit in obstetrics and gynaecology. Oxford: Blackwell (in press).

12 Steering Group on Health Services Information. First report to the Secretary of State. London: HMSO, 1982.

13 Parliamentary written answer. House of Commons Official Report (Hansard). 1993 March 16; col 760.
Rentary written answer. House of Co

14 Peckham M. Research for health. London: Department of Health, 1991 .

15 Maynard A. That's why the lady is a wimp. Health Service fournal 1993; January 28: 21.

16 Kerrison S, Packwood T, Buxton M. Medical audit: taking stock. Kings Fund working paper No 6. London: Kings Fund, 1993.

17 Department of Health. Quality in the NHS. (Press release 22 June 89/236.) London: Department of Health, 1989 .

18 Macfarlane A, Mugford M. Birth counts: statistics of pregnancy and childbirth. London: HMSO, 1984.

19 Enkin M, Chalmers I. Inquiries into perinatal deaths at area health authority level (a status report, winter 1979/80). health authority level (a status report,

20 Chalmers I, McIlwaine G. Perinatal audit and surveillance. Proceedings of the eighth study group of the Royal College of Obstetricians and Gynaecologists. London: Royal College of Obstetricians and Gynaecologists, 1980.

21 Department of Health. Perinatal, neonatal and infant mortality: government reply to the first report from the Social Services Committee, session 1988-89. London: HMSO, 1989. (Cm 741.)
22 Chalmers I. Inquiry into stillbirths and infant deaths. $B M \mathcal{F}$ 1989; 299: 339-40.

23 Macfarlane AJ. The downs and ups of infant mortality. BMF 1988; 296: 230-1

24 Macfarlane A, Johnson A, Mugford M. Epidemiology. In Roberton NRC, ed. Textbook of neonatalogy. London Churchill Livingstone, 1992: 3-27.

25 Audit commission. Children first: a study of hospital services. (Audit Commission NHS services report No 7.) London: HMSO, 1993.

26 NHS Management Executive. Local voices. (Executive letter EL(92)1.) London: Department of Health, 1992.

27 Garcia J. Getting consumers' views of maternity care: examples of how the OPCS survey manual can help. London: Department of Health, 1989 .

28 Macarthur C, Lewis M, Knox EG. Health after childbirth. London: HMSO, 1991.

29 Yudkin PL, Redman CWG. Obstetric audit using routinely collected computerised data. $B M \mathcal{F}$ 1990; 301: 1371-3.

30 Shaw CD. Quality assurance - what the colleges are doing. (Quality Assurance Project Reports KFC 86/63.) London: King's Fund Centre, 1986.

31 Joint Working Group of the British Association of Perinata Medicine and the Research Unit of the Royal College of Physicians. Development of audit measures and guidelines for good practice in the management of neonatal respiratory distress syndrome. Arch Dis Child 1992; 67: piratory

32 Chalmers I, Enkin M, Keirse MJNC, eds. Effective care in pregnancy and childbirth. Oxford: Oxford University Press, pregnancy.

33 Chalmers I, ed. Oxford database of perinatal trials. Version 1.3 disk issue 8. Oxford: Oxford University Press, 1992 34 Maresh M, Beard RW, Coombe D, et al. Selection of an obstetric data base for a microcomputer and its use for online production of birth notification forms, discharge summaries and perinatal audit. Brf Obstet Gynaecol 1983; 90 227-31.

35 Mugford M, Banfield P, O'Hanlon $M$. The effects of feedback of information on clinical practice: a review. $B M F$ 1991; 303: 398-402.

36 Banfield PJ, O'Hanlon M, Chapple JC, Mugford M. First report of the North West Thames region maternity statistics: 1989. London: North West Thames Regional Health Authority, 1991 .

37 Banfield PJ, O'Hanlon M, Chapple JC, Mugford M. Second report of the North West Thames region maternity statistics: 1990. London: North West Thames Regional Health Authority, 1992.

38 Banfield PJ, O'Hanlon M, Chapple JC, Mugford M, Beard RW. How clinicians respond to computer-generated statistics in maternity care. In: Richards B, ed. Current perspectives in healthcare computing conference. Weybridge: 